\title{
Current perspectives on the etiology and manifestation of the "silent" component of the Female Athlete Triad
}

This article was published in the following Dove Press journal:

International Journal of Women's Health

3 May 2014

Number of times this article has been viewed

\section{Rebecca J Mallinson \\ Mary Jane De Souza}

Department of Kinesiology, Women's Health and Exercise Laboratory in Noll Laboratory, Pennsylvania State University, University Park, PA, USA
Correspondence: Rebecca J Mallinson 206 Noll Laboratory, Department of Kinesiology, Penn State University, University Park, PA 16802, USA

$\mathrm{Tel}+\mathrm{I} 8148672510$

Fax + I 8I4865 4602

Email rjt199@psu.edu

\begin{abstract}
The Female Athlete Triad (Triad) represents a syndrome of three interrelated conditions that originate from chronically inadequate energy intake to compensate for energy expenditure; this environment results in insufficient stored energy to maintain physiological processes, a condition known as low energy availability. The physiological adaptations associated with low energy availability, in turn, contribute to menstrual cycle disturbances. The downstream effects of both low energy availability and suppressed estrogen concentrations synergistically impair bone health, leading to low bone mineral density, compromised bone structure and microarchitecture, and ultimately, a decrease in bone strength. Unlike the other components of the Triad, poor bone health often does not have overt symptoms, and therefore develops silently, unbeknownst to the athlete. Compromised bone health among female athletes increases the risk of fracture throughout the lifespan, highlighting the long-term health consequences of the Triad. The purpose of this review is to examine the current state of Triad research related to the third component of the Triad, ie, poor bone health, in an effort to summarize what we know, what we are learning, and what remains unknown.
\end{abstract}

Keywords: female athlete Triad, bone health, treatment

\section{Introduction}

Although habitual exercise is intrinsically beneficial to the health and well-being of girls and women, an imbalance between energy intake and expenditure, ie, energy expenditure that chronically exceeds energy intake, leads to physiological adaptations to conserve fuel, which ultimately contributes to clinically identifiable health consequences. ${ }^{1,2}$ The health consequences from the energy deficit are collectively referred to as the Female Athlete Triad (Triad), a syndrome composed of the following three interrelated conditions: low energy availability, menstrual dysfunction, and poor bone health (Figure 1). ${ }^{2}$ Among female athletes presenting with one or more components of the Triad, compromised bone mass and microarchitecture, ${ }^{3}$ which may increase the risk of fracture throughout the lifespan, ${ }^{2,4-6}$ and diminished cardiovascular health, as evidenced by impaired endothelial function and an unfavorable lipid profile, ${ }^{7,8}$ may also be observed. Notably, the presence of one or more conditions of the Triad has been identified in both elite and recreational athletes ranging in age from adolescents to young adults. .10

Energy availability is defined as the amount of energy available for physiological processes and activities of daily living after subtracting out the energy used for exercise training ${ }^{11}$ and is calculated as follows: (energy intake - exercise energy expenditure)/kg lean body mass. ${ }^{12,13}$ Low energy availability typically serves as the source of the other 


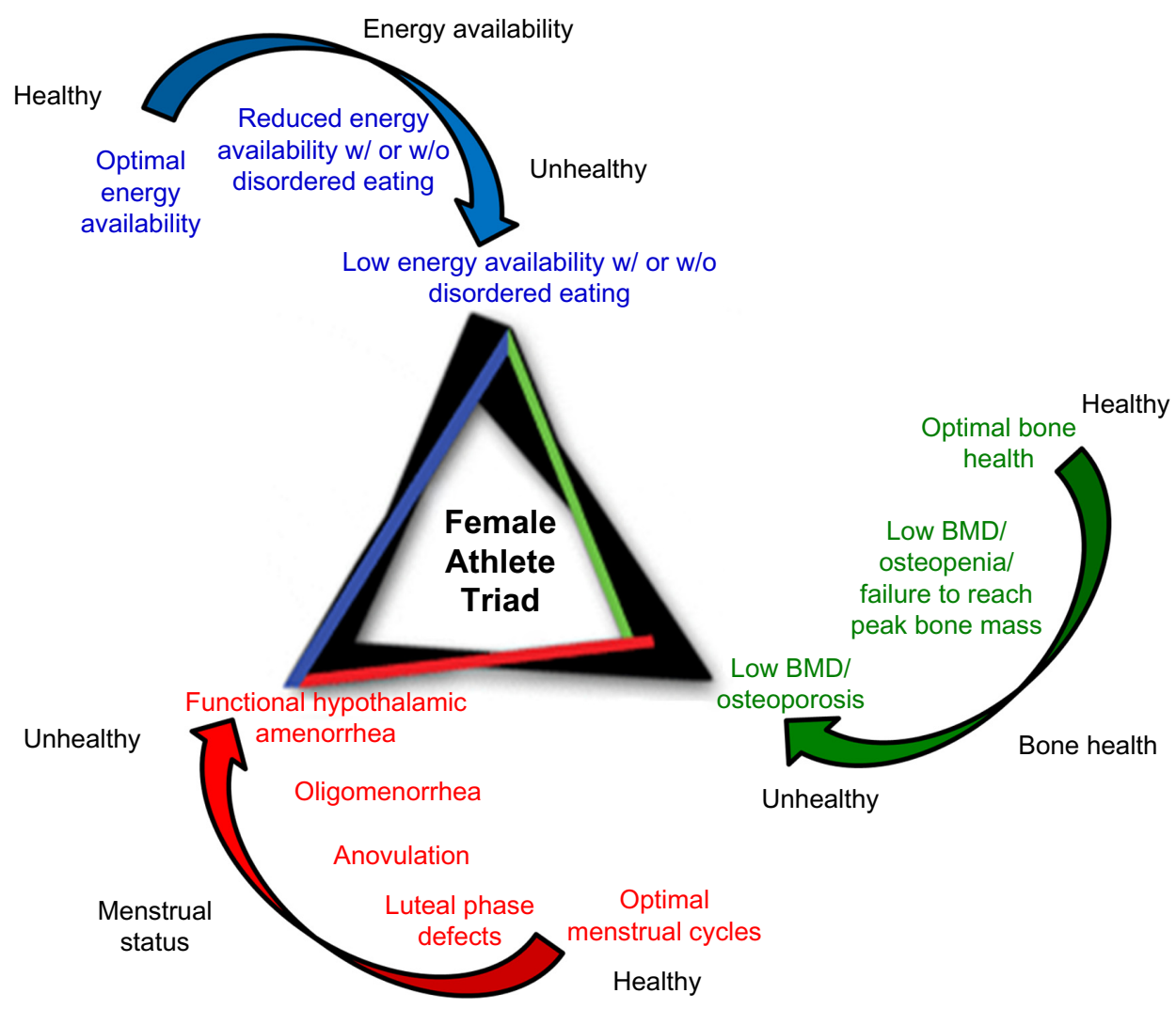

Figure I Spectra of the Female Athlete Triad. The three interrelated conditions of the Triad include low energy availability, menstrual dysfunction, and poor bone health. Each of these conditions may occur anywhere along a continuum from optimal health to a severe clinical endpoint.

Abbreviations: BMD, bone mineral density; w/, with; w/o, without.

two Triad components due to 1) its independent negative effects on reproductive function ${ }^{12-14}$ and bone health ${ }^{15}$ and 2) the detrimental effects that reproductive dysfunction caused by low energy availability has on bone health. ${ }^{16,17}$ It is often accompanied by energy conservation that is characterized by a decrease in resting energy expenditure ${ }^{14}$ and circulating concentrations of total triiodothyronine,,${ }^{14}$ insulin-like growth factor- $1,{ }^{18}$ and leptin, ${ }^{19}$ and an increase in ghrelin ${ }^{14,19,20}$ and peptide $\mathrm{YY}^{21} \mathrm{Via}$ neuroendocrine mechanisms, these metabolic adaptations can impair reproductive function and skeletal health. ${ }^{22-25}$

The menstrual function of a female athlete exists on a continuum (Figure 2) from optimal eumenorrheic and ovulatory cycles (26-35 days in length) to amenorrhea, defined as the absence of menses for at least 3 months (secondary amenorrhea $)^{1,26}$ or the failure to achieve menarche by the age of 15 years (primary amenorrhea). ${ }^{27}$ Under conditions of low energy availability, the hypothalamic-pituitary-ovarian axis is suppressed, most likely mediated through neural signals activated by reduced availability of metabolic fuels and altered concentrations of metabolic hormones. ${ }^{20-22,24,28,29}$ These neuroendocrine signals that indicate an energy-deficient state and a lack of available energy for all physiological processes disrupt the secretion of gonadotropin-releasing hormone from the hypothalamus, ${ }^{1,20,24}$ which in turn leads to altered secretion of gonadotropins from the anterior pituitary ${ }^{13,30-34}$ and suppressed production of the steroid hormones, estrogen and progesterone, from the ovaries. ${ }^{13,14,17,35}$ This cascade of altered reproductive hormones initiates a range of menstrual cycle disturbances from subtle to severe. Subtle menstrual cycle disturbances, which are also known as subclinical menstrual disturbances because they occur in the face of apparently regular cycles, encompass luteal phase defects and anovulation. ${ }^{26}$ Severe menstrual cycle disturbances are clinically identifiable due to changes in cycle length, and include oligomenorrhea, which is characterized by long (36-90 days) and inconsistent menstrual cycles, and amenorrhea. ${ }^{26}$ Amenorrhea caused by an energy deficit is referred to as functional hypothalamic amenorrhea; it is a result of a functional disorder of the hypothalamus characterized by hypothalamic suppression in the absence of a change in the structure of the hypothalamus. ${ }^{27,36}$

Low energy availability has also been identified as a determinant of bone health due to both energy-related and 


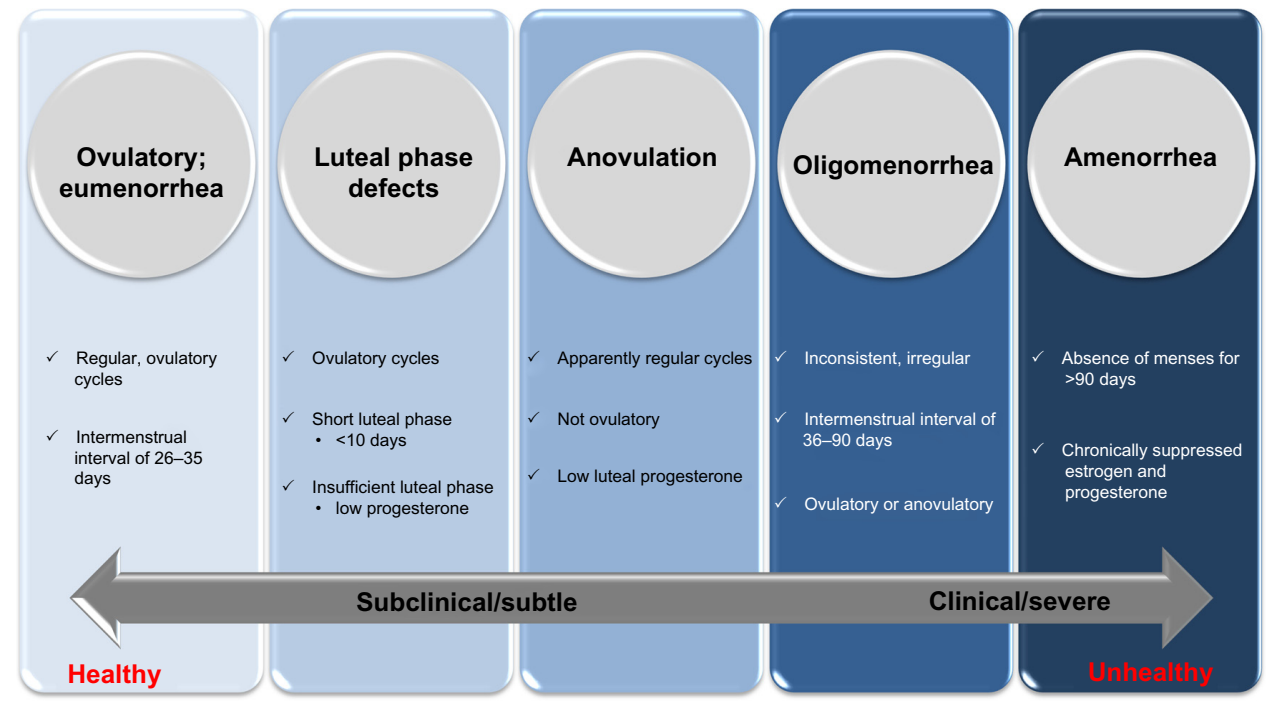

Figure 2 Continuum of menstrual cycle disturbances.

Notes: On the far left of the continuum is optimal menstrual health, which is characterized by regular ovulatory menstrual cycles that are $26-35$ days in length. The subclinical/subtle menstrual cycle disturbances include luteal phase defects and anovulation, which represent the least severe disturbances. Menstrual cycles with a luteal phase defect are ovulatory but characterized by a short luteal phase and/or insufficient progesterone production during the luteal phase. Menstrual cycles in which ovulation does not occur and progesterone concentrations are notably low are called anovulatory cycles. It must be noted that cycles that have a luteal phase defect or are anovulatory frequently appear to be regular cycles due to intermenstrual intervals of normal length. The clinical/severe menstrual cycle disturbances include oligomenorrhea which is characterized by long, inconsistent intermenstrual intervals and amenorrhea, the most severe menstrual cycle disturbance, which is characterized by the absence of menses for at least 3 months.

estrogen-related factors. Indeed, the influence of low energy availability on bone formation via hepatic suppression of insulin-like growth factor- $1^{18}$ and alteration of circulating concentrations of other metabolic hormones known to influence bone health, ie, leptin ${ }^{37}$ and peptide $Y Y,{ }^{17}$ compromises bone health. ${ }^{23}$ Furthermore, the suppressive effect of low energy availability on the reproductive axis and, consequently, menstrual function, which contributes to decreased serum concentrations of estrogen, causes an upregulation of bone resorption. ${ }^{16,38}$

As such, compromised bone health represents the downstream effects of both low energy availability and menstrual dysfunction. Due to the suppression of bone formation ${ }^{15,16}$ and upregulation of bone resorption ${ }^{15}$ related to an energy deficit and the increase in bone resorption related to an estrogen deficit, ${ }^{16,38}$ it must be noted that low energy availability and menstrual dysfunction demonstrate independent and synergistic effects on bone health. Unlike the other components of the Female Athlete Triad, poor bone health often does not have overt symptoms, and therefore develops silently, unbeknownst to the athlete. As elegantly described in a recent review paper by Gibbs et al, ${ }^{10}$ low bone mineral density (BMD) was observed in $0 \%-15.4 \%$ of female athletes when defined as a $Z$-score $\leq-2.0$ and $0 \%-39.8 \%$ when defined as a $Z$-score between -1.0 and -2.0 . Numerous investigators have reported that amenorrheic athletes present with lower BMD than their eumenorrheic counterparts, particularly at the highly trabecularized lumbar spine, $, 317,39-45$ and strong evidence exists that alterations in metabolic and reproductive hormones caused by an energy deficit contribute to the uncoupling of bone metabolism and subsequent low bone mass. ${ }^{15-17,23}$

With the advent of improved imaging techniques and identification of the clinical consequences of low BMD among female athletes, current Triad research has focused extensively on the bone health component, exploring beyond BMD and assessing bone geometry and microarchitecture, the impact of sport type and loading modality on bone health, the factors that are the strongest contributors to poor bone health among female athletes, and stress fractures, which are a clinical outcome of poor bone health. Despite recent important advances in knowledge about bone health among female athletes presenting with one or more components of the Triad, questions without definitive answers remain, particularly pertaining to appropriate treatment strategies for poor bone health among female athletes and whether restoration of optimal bone health is possible among female athletes with low bone mass and/or impaired bone microarchitecture. As such, the purpose of this review is to examine the current state of Triad research related to the third component of the Triad, ie, poor bone health, in an effort to summarize what we know, what we are learning, and what remains unknown. Several investigators have recently published review articles on the current findings, prevalence, and treatment of the Triad as a 
whole, ${ }^{10,46,47}$ and readers are encouraged to reference these sources for more information about the energy availability and menstrual dysfunction components of the Triad.

\section{What are the recent discoveries? Bone geometry and microarchitecture of female athletes}

To date, the majority of researchers who have assessed Triad-related detriments in bone health have used measurements obtained from dual-photon absorptiometry or dual-energy x-ray absorptiometry (DXA), both of which are two-dimensional imaging techniques. ${ }^{17,39-45}$ Although DXA is currently the clinical gold standard for diagnosis of osteopenia and osteoporosis, it is limited by the twodimensional nature of its areal BMD measurements and is not capable of assessing true BMD, ie, volumetric BMD, or bone geometry. ${ }^{48}$ As such, investigators have explored bone health among athletes with Triad perturbations via threedimensional bone imaging, ie, primarily peripheral quantitative computed tomography (pQCT). ${ }^{3,49-51}$ Assessment of bone structure with three-dimensional imaging has revealed deterioration of the trabecular microarchitecture, characterized by lower trabecular number and greater trabecular spacing, at the distal tibia among amenorrheic adolescent and young adult athletes compared with eumenorrheic athletes and nonathletic controls. ${ }^{3}$

Of particular interest, however, is that amenorrheic athletes appear to acquire some of the osteogenic benefits of habitual exercise in that bone size, referred to as total bone area, at the distal tibia is greater among amenorrheic athletes compared with sedentary controls and similar to that observed in eumenorrheic athletes. ${ }^{3}$ Because bone strength, or the resistance of bone to bending forces, is equivalent to the crosssectional radius of the bone to the fourth power, ${ }^{52,53}$ bone size is an extremely important and influential component of bone strength. This fact highlights that despite menstrual dysfunction, habitual exercise may be partially protective against a reduction in bone strength that is typical with an energy deficit and menstrual dysfunction. It must be noted, however, that despite the larger total bone area, assessment of the components of total bone, ie, trabecular and cortical bone, reveals that amenorrheic athletes have a greater relative trabecular area ( $\%$ of the total area) but a smaller relative cortical area at the distal tibia compared with sedentary controls. ${ }^{3,49}$ These results suggest that, despite the larger bone size, the thickness of the cortical shell and, therefore, mineralization of the cortical bone, may be compromised in amenorrheic athletes compared with nonathletic controls. ${ }^{49}$
In a slightly different model consisting of retired elite gymnasts (mean age 22.3 years) grouped according to history of amenorrhea, Ducher et al ${ }^{50}$ demonstrated that the bone strength index, a measure of the bone's resistance to compressive forces, at the distal radius was significantly lower among retired gymnasts with a history of amenorrhea compared with retired gymnasts without a history of amenorrhea. On the other hand, there was a trend $(P<0.09)$ towards a greater strength strain index, a measure of resistance against bending and torsional forces, ${ }^{54-56}$ at the proximal tibia among retired gymnasts with a history of amenorrhea compared with retired gymnasts without a history of amenorrhea. ${ }^{50} \mathrm{As}$ such, it appears that, among amenorrheic athletes, areas of bone with a greater trabecular content, such as distal sites, may be more susceptible to decrements in strength compared with proximal sites that are composed primarily of cortical bone and are perhaps more sensitive to changes in bone geometry, ie, increases in bone size, initiated from muscle and gravitational forces during habitual exercise.

Although pQCT, unlike DXA, allows for the estimation of bone strength, it is primarily used in research settings and therefore has limited clinical availability. ${ }^{53}$ For this reason, algorithms that have been developed for DXA to estimate bone geometry at the hip have provided a clinically-useful alternative to three-dimensional imaging techniques. ${ }^{57-59}$ Recent assessment of hip geometry using DXA in athletes grouped according to menstrual status revealed that the crosssectional area of the femoral neck and shaft was significantly smaller in oligo/amenorrheic athletes compared with eumenorrheic athletes but similar to that observed in nonathletes. ${ }^{60,61}$ Unlike peripheral measurements of bone area, ${ }^{3}$ these results suggest that bone geometry at the femoral neck, a common site of osteoporotic fracture ${ }^{62}$ and a potential site for debilitating stress fractures,${ }^{63}$ may be compromised by menstrual dysfunction. It must be noted, however, that this difference in cross-sectional area was lost after adjusting for lean body mass, ${ }^{60}$ and other investigators have observed no difference in femoral neck cross-sectional area between amenorrheic and eumenorrheic athletes. ${ }^{45}$

\section{Sport loading modality, bone health, and menstrual status}

In light of the aforementioned findings regarding bone structure, the strong influence of sport loading modality must not be overlooked. Findings from several investigations conducted by Nikander et a ${ }^{64-67}$ have demonstrated that female athletes who participate in high impact and odd impact sports present with favorable bone characteristics that are not 
observed among nonathletic referents and athletes participating in nonimpact sports such as swimming and cycling. For example, healthy premenopausal athletes of high impact (volleyball, hurdling), odd impact (soccer, speed skating, step aerobics, squash), high magnitude (weightlifting), and repetitive low impact (orienteering, cross-country skiing) sports present with significantly greater areal BMD and estimated cross-sectional area of the femoral neck compared with nonathletic controls; whereas, swimmers and cyclists demonstrate no difference in these parameters compared with the referents.$^{64}$ It must also be noted that athletes in the highimpact and odd-impact groups appear to reap the greatest skeletal benefits from loading at the femoral neck, with an increase above the referent group of $19.9 \%-28.7 \%$ for areal BMD and $18.0 \%-26.5 \%$ for cross-sectional area compared with an increase of $14.2 \%$ and $11.9 \%$ for areal BMD and cross-sectional area, respectively, for athletes in the repetitive low-impact group. ${ }^{64}$ Muscle performance-related joint moment and loading modality, ie, high impact, odd impact, and nonimpact, are among the strongest predictors of bone structure and estimated bone strength at the tibia, radius, and humerus among women, ${ }^{65}$ highlighting the important contributions of muscle forces and sport type, which are intricately linked, to bone health and fracture risk among female athletes.

As such, female athletes with low energy availability and menstrual dysfunction represent a unique environment for bone health due to the opposing actions of habitual physical activity and suppressed metabolic and reproductive environments on bone quantity (mass) and quality (structure). Interestingly, habitual physical activity may have a protective effect on weight-bearing bones such as the femur and tibia in amenorrheic athletes, or at least attenuate the detrimental effects of a poor metabolic and reproductive environment on bone health; however, the protective effect may be lost at nonweight-bearing sites such as the lumbar spine and radius., ${ }^{3,43}$ Among adolescent and young adult female athletes who primarily participate in aerobic weightbearing training of the legs, running, or other endurance training, the BMD $Z$-score at the lumbar spine is significantly lower among amenorrheic athletes than in eumenorrheic athletes and sedentary controls; $;^{3,43}$ however, BMD Z-scores at the femoral neck and hip are lower than their eumenorrheic counterparts but similar to sedentary controls, ${ }^{3,43}$ suggesting that the loss or failure to accrue bone mass at the weight-bearing femur is attenuated by habitual physical activity. Further, amenorrheic athletes demonstrate greater total and trabecular bone area at the distal tibia compared with sedentary girls and women, a difference that is lost at the distal radius. ${ }^{3}$

It is imperative to note, however, that the response of bone mass and structure to the antithetical influence of habitual exercise and exercise-associated menstrual dysfunction may be dependent on the type of activity that is regularly performed by the athletes. To date, one study has explored the combined influence of loading modality and menstrual status on bone health in female high school athletes. ${ }^{68}$ The athletes were categorized as eumenorrheic or oligo/amenorrheic and were separated into two groups according to sport type, including repetitive/nonimpact sports (distance running and swimming) and high/odd impact sports (soccer, softball, volleyball, lacrosse, tennis, track sprinters, and jumpers). ${ }^{68}$ Among regularly-menstruating athletes, those participating in high/odd impact sports demonstrated significantly greater hip BMD compared with repetitive/nonimpact athletes. ${ }^{68}$ Similarly, among oligo/amenorrheic athletes, lumbar spine $Z$-score was significantly greater among those participating in high/odd impact sports compared with those participating in repetitive nonimpact sports. ${ }^{68}$ Further, lumbar spine BMD (both absolute BMD and Z-score) was significantly greater in eumenorrheic, high/odd impact athletes than in oligo/ amenorrheic, repetitive/nonimpact athletes. ${ }^{68}$ No differences in absolute BMD or $Z$-score were observed between athletes of differing menstrual status (eumenorrheic versus oligo/ amenorrheic) who were participating in sports of a similar loading modality. ${ }^{68}$ These results confirm previous reports of the strong influence of sport loading modality on the BMD of athletes, ${ }^{64-67}$ yet also reveal that menstrual status may not strongly discriminate among athletes participating in sports of similar loading modality. Rather, the largest differences may be observed when loading modality and menstrual status are combined, such that those athletes participating in the most osteogenic activities and presenting with the most regular menstrual cycles demonstrate greater bone mass than athletes who participate in less osteogenic sports and present with irregular or absent menstrual cycles.

\section{Primary contributors to bone mass and structure in female athletes}

As previously mentioned, amenorrheic athletes frequently present with low areal BMD at the lumbar spine, , $^{317,39-45}$ reduced trabecular volumetric BMD and bone strength index at the distal radius, ${ }^{50}$ and deterioration of the trabecular microarchitecture at the distal tibia ${ }^{3}$ when compared with their eumenorrheic counterparts. Taken together, these results suggest that sites of primarily trabecular bone 
are sensitive to changes in the hormonal environment and therefore are susceptible to poor bone quantity (mass) and quality (structure) and, subsequently, increased fracture risk. In fact, a cross-sectional analysis of amenorrheic and eumenorrheic exercising women revealed that upon consideration of reproductive function, metabolic hormones, and body composition, the strongest predictors of lumbar spine areal BMD were markers of reproductive function, ie, mean estrogen concentration during a menstrual cycle and age of menarche, which together explained $25.5 \%$ of the variance in areal BMD at this site. ${ }^{45}$ Lean body mass was the strongest predictor of areal BMD and estimated geometry at weight-bearing sites, explaining $8.5 \%-34.8 \%$ of the variance in areal BMD and estimated geometry at the femoral neck and total hip. ${ }^{45}$ Notably, the metabolic hormone, leptin, was also a significant predictor of femoral neck cross-sectional area. ${ }^{45}$ These results demonstrate the importance of energy availability and therefore metabolic status, body mass, and menstrual function on bone health, including both densitometric and geometrical variables, which are two important components of bone strength. Further, age of menarche was a significant predictor of both areal BMD and bone geometry at the lumbar spine and hip region, highlighting the importance of estrogen exposure during adolescence for BMD and bone geometry, and therefore bone strength, during adulthood. ${ }^{45}$

In fact, the influence of age of menarche on BMD must not be underestimated. In adolescent girls, bone mineral accrual occurs rapidly between the ages of 11 and 14 years ${ }^{69,70}$ and slows drastically after the age of 16 years. ${ }^{69}$ Further, the majority of peak bone mass is attained by the age of 18 years. ${ }^{38,71,72}$ Consequently, the optimal window to accrue bone mass may be missed or compromised in the case of late menarche, defined as the onset of menses occurring at age 15 years or older. ${ }^{27}$ Optimal accrual of bone mineral and attainment of a healthy peak bone mass are dependent on normal endocrine function which includes, but is not limited to, adequate circulating concentrations of sex steroids. ${ }^{38,72}$ Because adolescence represents a critical window for gains in bone mass, adolescent athletes who experience primary and/or secondary amenorrhea may be at risk for worse skeletal consequences than adult athletes who are currently presenting with secondary amenorrhea but have a history of regular menses during adolescence.

In an elegant analysis of a large sample of exercising adolescent girls and young adult women, late menarche was one of the strongest predictors of low BMD (Z-score $<-1$ and $\leq-2)$. ${ }^{73}$ In addition, lean sport participation and lean body mass, after adjusting for body mass index, menstrual status, dietary restraint status, and age, were also significant predictors of low BMD $(Z$-score $<-1$ and $\leq-2)$. $^{73}$ Furthermore, adolescents and women with late menarche were four times more likely to have low BMD. ${ }^{73}$ An additional concern is that $55.2 \%$ and $13.8 \%$ of the girls and women with late menarche had low BMD as defined by a $Z$-score $<-1$ and $\leq-2$, respectively. ${ }^{73}$ Other Triad risk factors that were associated with low BMD in this sample included the presence of oligo/amenorrhea, low body mass index, and low body weight, such that those presenting with these risk factors were 2-5 times more likely to demonstrate low BMD. ${ }^{73}$

A closer look at bone type and structure confirms the importance of age of menarche and lean mass for bone health and perhaps provides a glimpse into the underlying mechanism that explains the aforementioned influence of age of menarche and lean mass on DXA-derived areal BMD and bone geometry. Among a sample of adolescent athletes of varying menstrual status and nonathletic controls, age of menarche, bone age, lean mass, and menstrual/athletic status were entered into a model to identify significant determinants $(P<0.05)$ of volumetric BMD and bone structure. ${ }^{3}$ Age of menarche was a significant predictor of trabecular and cortical volumetric BMD, trabecular and cortical area, and cortical thickness at the radius and tibia. ${ }^{3}$ Further, trabecular microarchitecture at the radius, including trabecular thickness and trabecular spacing, was determined by age of menarche. ${ }^{3}$ Lean mass, on the other hand, was a significant predictor of cortical and trabecular area at the radius and tibia in addition to total area and cortical perimeter at both sites. ${ }^{3}$ Further analysis of the influence of age of menarche and lean mass on bone health revealed that both factors were significant predictors of stiffness and failure load at both the radius and tibia. ${ }^{49}$ Figure 3 provides a summary of the parameters of BMD and bone structure that are predicted by age of menarche and lean mass., ${ }^{3,45}$ In sum, a surrogate marker of reproductive status, ie, age of menarche, is a significant predictor of densitometric, structural, and microarchitectural variables, emphasizing the importance of optimal menstrual status during the critical adolescent window. Lean mass, on the other hand, is primarily a significant predictor of variables pertaining to bone size and area. Together, these results demonstrate the inextricable link between conditions of the Triad, specifically the detrimental impact that low energy availability, which typically leads to low body weight and menstrual dysfunction characterized by either primary or secondary amenorrhea, has on bone health. 


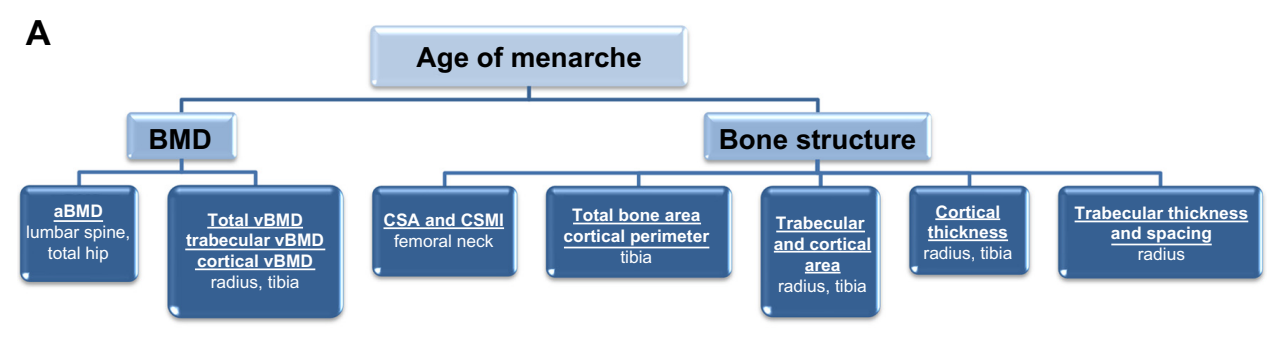

B

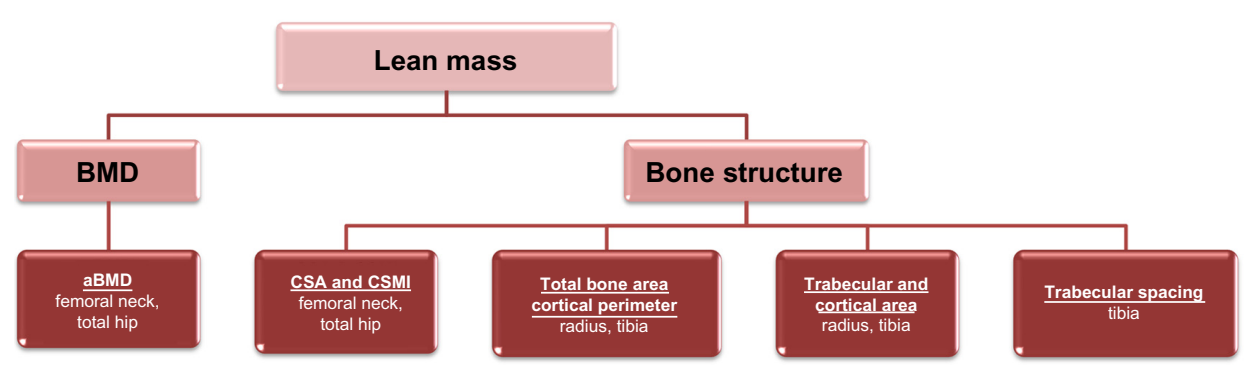

Figure 3 Strong predictors of bone mineral density and bone structure in exercising women according to recent investigations.

Notes: (A) Parameters of bone mineral density and bone structure that are predicted by age of menarche. (B) Parameters of bone mineral density and bone structure that are predicted by lean mass. Data from Ackerman et $\mathrm{al}^{3}$ and Mallinson et al..$^{45}$

Abbreviations: aBMD, areal bone mineral density; vBMD, volumetric bone mineral density; CSA, cross-sectional area; CSMI, cross-sectional moment of inertia.

\section{Stress fractures}

Stress fractures are often a clinical manifestation of low bone mass. ${ }^{4}$ These debilitating injuries occur as a result of an accumulation of microcracks under conditions of repetitive activities such as distance running, inadequate rest, or poor nutrition. ${ }^{74}$ The development of microcracks within bone is a normal part of the continual remodeling process, ${ }^{74}$ and these microcracks develop as a result of repeated force on bone through loading. ${ }^{74}$ Subsequently, osteoclasts resorb the area of bone with the microcracks, and osteoblasts form new bone at the site. ${ }^{74}$ However, in the event of the aforementioned conditions, appropriate healing of microcracks may not be realized with inadequate rest and/or altered bone metabolism, ie, increased bone resorption and decreased bone formation, as is evident in an energy-deficient state. ${ }^{15,16,74}$ Stress fractures are characterized by pain and lost training time, ${ }^{75,76}$ and can lead to serious health consequences such as complete fracture and malunion or disunion of the bone, thereby requiring surgery and prolonging healing time, if not identified and treated in a timely manner. ${ }^{63,76}$ As clearly outlined in a published case study of an adolescent runner who experienced a displaced femoral neck fracture while competing, lack of appropriate treatment of these injuries has significant implications and can lead to long-term consequences including, but not limited to, reduced mobility, limited participation in sports, and poor healing. ${ }^{63}$

In a 5 -year prospective analysis of collegiate track and field and cross-country athletes $(n=211), 16 \%$ of athletes sustained a bone stress injury. ${ }^{77}$ Of these injured athletes, the majority (65\%) were female, a finding that agrees with the observations of other investigators. ${ }^{78-80}$ Factors associated with the Female Athlete Triad have also been observed to be significant predictors of stress fracture risk, ${ }^{4,77,81}$ perhaps serving as one underlying reason, among several potential reasons, for the comparatively greater prevalence of stress fractures in women compared with men. Analysis of several Triad risk factors in a large sample of female athletes ( $n=259)$ revealed that low BMD $(Z$-score $<-1)$, participation in $\geq 12$ hours of purposeful exercise per week, and body mass index $<21.0 \mathrm{~kg} / \mathrm{m}^{2}$ were observed more frequently among female athletes with a physician-diagnosed bone stress injury $(14.7 \%-21.0 \%)$ compared with noninjured athletes (3.4\%-7.6\%). ${ }^{4}$ Furthermore, female athletes who presented with any of these three Triad risk factors were 2.4-4.9 times more likely to sustain a bone stress injury, and the combination of all three increased the risk of injury by 6.8 -fold. ${ }^{4}$ In a sample of female runners and triathletes, a higher prevalence of oligo/amenorrhea was observed among athletes with a history of stress fracture compared with athletes without a history of fracture.$^{81}$ Furthermore, the athletes who reported current oligo/amenorrhea were 4.7 times more likely to experience a stress fracture compared with eumenorrheic athletes. ${ }^{81}$ Not only are athletes with menstrual dysfunction at higher risk for stress fracture, but they may also be at risk for more severe stress fractures. ${ }^{77}$ Stress fracture diagnosis 
via magnetic resonance imaging revealed that female athletes with oligo/amenorrhea suffered more severe stress fractures and more stress injuries at trabecular bone sites (versus cortical bone sites) when compared with eumenorrheic athletes. ${ }^{77}$ Notably, stress injuries of greater severity and at trabecular bone sites demonstrated longer recovery and time to full return to sport compared with less severe injuries and those injuries occurring at cortical bone sites. ${ }^{77}$ In sum, these results provide further evidence of the inextricable link among components of the Triad, ie, the robust influence of low energy availability and menstrual dysfunction on bone health, and the clinical consequences that can flow from the Triad if symptoms are left unnoticed or ignored.

\section{What remains unknown?}

\section{Does reversal of low energy availability and menstrual dysfunction among athletes with the Triad allow for complete recovery of bone health?}

Research conducted to date has clearly established that bone health is compromised in an energy-deficient and estrogendeficient environment. What is unclear, and is perhaps the more important question, is the extent to which bone health, including both bone quantity (bone mass) and bone quality (bone structure), can be recovered with improvements in the energetic and reproductive environments in affected girls and women. Exploration of the reversal of low bone mass among female athletes or recreationally active women experiencing menstrual dysfunction has been limited to case studies ${ }^{82-84}$ and follow-up investigations ${ }^{85-89}$ (Table 1). However, studies in a similar but more severe model of energy deficiency, ie, anorexia nervosa, provide interesting perspectives on the question. ${ }^{90-93}$

Published case studies of endurance athletes with amenorrhea and, frequently, low BMD demonstrated increases in hip and spine areal BMD of $0.8 \%-25.5 \%$ after weight gain and over the course of 3-8 years. ${ }^{82,83}$ Likewise, although a 12-month intervention of increased caloric intake designed to improve energy status in two recreationally active, young amenorrheic women demonstrated no clinically significant increase in areal BMD, a 50\% increase in markers of bone formation was observed, suggesting that a clinically significant increase in areal BMD may have occurred with an intervention of longer duration. ${ }^{84}$ Similarly, in female athletes who were monitored for 1.3-5 years, an increase in lumbar spine areal BMD or $Z$-score was observed in amenorrheic athletes who gained weight ${ }^{86,87}$ or fat mass ${ }^{89}$ and, for the majority, also resumed menses. ${ }^{86,87,89}$ Importantly, the BMD of these athletes did not normalize to that of regularly-menstruating athletes during the 15-24-month follow-up period. ${ }^{86,87,89}$ These results are in agreement with an 8-year follow-up investigation that revealed persistently low lumbar spine areal BMD in formerly amenorrheic and oligomenorrheic athletes who had experienced regular menstrual cycles and/or used oral contraceptives for several years. ${ }^{85}$ It must be noted that all but one of these follow-up studies ${ }^{85,86,89}$ solely included exercising, young adult women. In the one study that included adolescent athletes, ${ }^{87}$ the mean age of the study population at baseline was 22.2 years due to the large age range of the study participants (13-29 years). Given the importance of adequate estrogen concentrations during the adolescent years for optimal bone mineral accrual and attainment of a healthy peak bone mass, ${ }^{38,72}$ it is possible that recovery of bone health in athletes with amenorrhea during adolescence (ie, primary and/or secondary amenorrhea) versus athletes with amenorrhea during young adulthood (secondary amenorrhea with regular menses during adolescence) may be different. The time course of the reversal of energy availability and menstrual dysfunction during adolescence or adulthood most likely plays a role in successful recovery of bone health.

To date, there are no studies that have followed adolescent athletes with primary amenorrhea/late menarche through their third decade of life, assessing BMD at regular intervals and comparing it with the BMD of both regularly menstruating athletes and nonathletic controls, to determine if bone mineral accrual will continue later in life in athletes with late menarche, provided that optimal energy availability and menstrual function is restored. Furthermore, there have been no reports of interventions designed to reverse the energy and estrogen deficiency in amenorrheic female athletes, with the long-term goal of improving bone health. In our laboratory, a prospective, randomized controlled trial is underway examining the effects of increased caloric intake on recovery of menstrual function and bone health in exercising women with exercise-associated menstrual disturbances. Results from this trial will be reported in the literature in the future. Such studies, however, have been undertaken in the anorexic population, and will be discussed here.

In girls and women with anorexia nervosa, nonpharmacological approaches to treatment that have resulted in weight gain concomitant with resumption of menses have contributed to annual increases in lumbar spine and hip areal BMD of 3.1\% and 1.8\%, respectively. ${ }^{90}$ Furthermore, anorexic girls who gained weight and resumed menses did not demonstrate further decreases in lumbar spine 


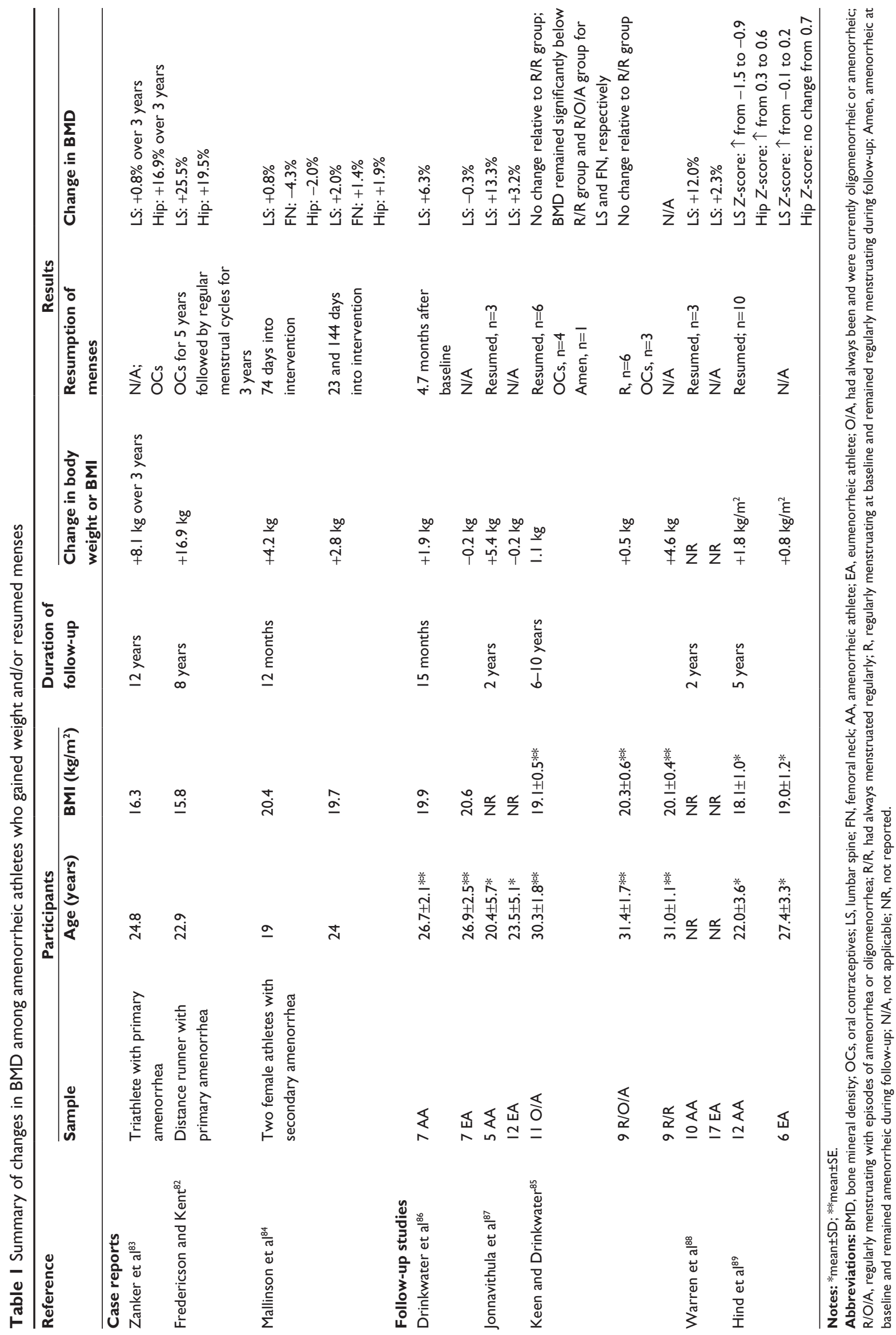


areal BMD. ${ }^{91}$ Interestingly, beneficial bone health outcomes may be observed as a result of weight gain and resumption of menses that occur independently rather than concomitantly. For example, both spine ${ }^{92,93}$ and hip ${ }^{90,93}$ areal BMD increased in anorexic women who gained weight independent of resumption of menses. Conversely, a significant increase in lumbar spine areal BMD was observed in anorexic women who resumed menses without concomitant weight gain. ${ }^{90}$ As such, a nonpharmacological approach that focuses on increased energy intake with the goals of weight gain and resumption of menses has the potential to be an effective treatment strategy among athletes with low BMD caused by the synergistic effects of energy deficiency and estrogen deficiency.

\section{What is the most appropriate and effective treatment for low bone mass and compromised bone structure in female athletes with the Triad? Nonpharmacological treatment}

The nonpharmacological approach of an increase in caloric intake, a decrease in energy expenditure, or both in order to promote weight gain and resumption of menstrual function is the first goal of treatment for the Triad. This strategy is the first approach to treatment since the initial source of the Triad, ie, low energy availability, can only be addressed by increasing energy availability. ${ }^{2,94}$ As previously highlighted, improvements in areal BMD of $1 \%-26 \%$ and bone metabolism of $50 \%$ were observed with weight gain and resumption of menses, both independently and concomitantly, among case studies of female athletes, ${ }^{82-84}$ suggesting that a nonpharmacological approach may be effective. However, conclusions about effectiveness cannot be drawn due to the lack of controlled prospective interventions. More research is necessary to determine the time course of changes in BMD and bone structure in conjunction with weight gain and resumption of menses and the specific nutritional intervention that is most effective for improving BMD and bone microarchitecture in athletes with Triad-related decrements in bone health.

In conjunction with nonpharmacological treatment, adequate intakes of calcium (1,000-1,300 mg/day $)^{95,96}$ and vitamin D (600-1,000 IU/day) $)^{95-97}$ are also important for bone mineralization. ${ }^{2}$ Although intake of these nutrients should ideally come from calcium-rich foods, supplementation may be necessary to provide adequate amounts of these micronutrients. ${ }^{2}$
An additional nonpharmacological treatment approach to be considered is participation in resistance training and/or weight-bearing exercise, which are both established to be osteogenic, particularly when the weight-bearing activity involves high ground reaction forces and/or heterogeneous and uncustomary patterns of loading. ${ }^{64-67}$ Although energy expenditure and intake must be closely monitored with the addition of this component to prevent reinitiation of an energy-deficient state, the gain in lean mass that may accompany resistance training ${ }^{98}$ and the skeletal adaptations that may accompany high impact or odd impact weight-bearing exercise $^{64-67}$ may be beneficial for improvements in bone health. However, caution must be exercised when implementing high-impact activity in female athletes with low BMD due to the potential for fracture. ${ }^{99}$

Among exercising women, lean mass has been demonstrated to be a strong predictor of bone mass and geometry. ${ }^{3,45}$ Prospective evaluation of skeletal recovery in anorexic women for 6-69 months revealed that percent change in fat-free mass was a significant positive predictor of the change in hip and lumbar spine areal BMD. ${ }^{90}$ Furthermore, lean mass was a significant predictor of change in femoral shaft cross-sectional area from the age of 17-21.5 years among female adolescents, ${ }^{100}$ suggesting that an increase in lean mass may aid improvement in bone strength and reduced risk for fracture.

\section{Pharmacological treatment}

The primary pharmacological agents that have been investigated to improve low bone mass in women with functional hypothalamic amenorrhea, including both athletes and anorexic women, encompass traditional treatments such as combined oral contraceptives (COC) $)^{101-115}$ and estrogen therapy, ${ }^{112,116-122}$ and more novel treatments such as androgens, ${ }^{105,123-125}$ recombinant human insulin-like growth factor- $1^{106}$ and leptin,,$^{29,37,126}$ and bisphosphonates. ${ }^{125,127,128}$ In 2008, a thorough systematic review outlined current pharmacological treatments for low bone mass in women with functional hypothalamic amenorrhea and described in detail the efficacy of various treatments based on published reports from 1960 to $2007 .{ }^{129}$ Readers are encouraged to refer to this review paper for an overview of studies on this topic dating to 2007. In this paper, we aim to provide an update on the current state of pharmacological treatment for low bone mass in female athletes based on research that has been published since 2007. The majority of published studies to date that describe the impact of pharmacological treatment on low bone mass in amenorrheic women have been conducted in the 
anorexic population, highlighting the need for more research in this area, specifically among female athletes.

\section{Combined oral contraceptives}

As of 2007, 13 studies including randomized controlled trials $(n=6),{ }^{102-107}$ cohort studies $(n=2),{ }^{108,109}$ prospective studies $(n=4),{ }^{110-113}$ and one cross-sectional study ${ }^{114}$ have explored the impact of treatment with COC on bone mass in women with functional hypothalamic amenorrhea. Six of these studies were conducted in athletes with functional hypothalamic amenorrhea, ${ }^{102-104,108,109,113}$ and seven were conducted in anorexic women or adolescents. ${ }^{105-107,110-112,114}$ Results from the six studies in athletes with functional hypothalamic amenorrhea $^{102-104,108,109,113}$ and one study in anorexic women ${ }^{114}$ demonstrated that COC had a beneficial impact on BMD; however, results from the remaining six studies, ${ }^{105-107,110-112}$ which were all conducted in anorexic women or adolescents, indicated no effect of COC on BMD. ${ }^{129}$ These results highlight the equivocal nature of the efficacy of COC in improving bone health among women with functional hypothalamic amenorrhea associated with exercise or anorexia. ${ }^{129}$

Recent reports of the effect of treatment with $\mathrm{COC}$ on bone mass in female athletes with exercise-associated functional hypothalamic amenorrhea are limited to one randomized controlled trial. In an intention-to-treat analysis, Cobb et $\mathrm{al}^{101}$ observed no effect of treatment with $\mathrm{COC}$ on areal $\mathrm{BMD}$ or bone mineral content at the lumbar spine in competitive female runners. It must be noted, however, that both the COC group and the control group included eumenorrheic, oligomenorrheic, and amenorrheic athletes. ${ }^{101}$ A subanalysis of the amenorrheic athletes alone revealed that athletes in the COC treatment group and those in the control group demonstrated a significant increase in areal BMD at the lumbar spine, again indicating the absence of a treatment effect in amenorrheic athletes. ${ }^{101}$

\section{Estrogen therapy}

Prior to 2007, six studies, including randomized controlled trials $(n=2),{ }^{16,117}$ and retrospective $(n=1),{ }^{118}$ prospective $(\mathrm{n}=1),{ }^{112}$ cross-sectional $(\mathrm{n}=1),{ }^{119}$ and case studies $(\mathrm{n}=1),{ }^{120}$ investigated the impact of estrogen therapy on bone mass in women with functional hypothalamic amenorrhea associated with either exercise $(n=3)^{116-118}$ or anorexia nervosa $(n=3) .{ }^{112,119,120}$ Similar to the results for COC treatment, half of the studies $(n=3)^{118-120}$ demonstrated that estrogen therapy had a beneficial impact on BMD; whereas, the other half $(n=3)^{112,116,117}$ showed no positive effect of estrogen therapy on BMD. ${ }^{129}$
No recent studies have been published exploring the impact of estrogen therapy on BMD in female athletes. Recently published results of the effect of estrogen therapy on BMD in anorexic adolescents or women confirmed the previous equivocal findings. ${ }^{121,122}$ Adolescent girls with anorexia who received either transdermal $17 \beta$-estradiol (mature girls, $\mathrm{n}=96$ ) or incremental low-dose oral ethinyl estradiol (immature girls, $\mathrm{n}=14$ ) for 18 months had a significant increase in lumbar spine and hip areal BMD compared with anorexic girls treated with placebo. ${ }^{121}$ On the other hand, in an older population of anorexic patients (mean age 25.3 years) presenting with osteoporosis, treatment with $17 \beta$ estradiol for 2 years did not result in a significant increase in areal BMD at any site and the change in areal BMD was not different than the change observed in the nontreated group. ${ }^{122}$

These recent results for both COC and estrogen therapy in women with functional hypothalamic amenorrhea are in agreement with the conclusions drawn from a meta-analysis that explored the influence of estrogen preparations on bone health in young women with anorexia nervosa. ${ }^{130}$ Although treatment with estrogen preparations in anorexic women appears to result in attenuated bone loss at the lumbar spine (but not femoral neck) when compared with those not receiving treatment, the evidence is weak, thereby confirming the inconclusive influence of COC or estrogen therapy on bone health in anorexic women. These results are in contrast with the mean $2.5 \%$ annual increase in areal BMD among anorexic women who gained weight and resumed menses, ${ }^{90}$ highlighting the importance of nutritional interventions that result in weight gain and resumption of menses in order to improve bone health in energy-deficient and estrogendeficient populations. ${ }^{130}$

\section{Androgen therapy}

As of 2007, androgen therapy had only been investigated in anorexic women. Although favorable changes in bone turnover markers occurred following androgen therapy, ${ }^{105,123,124}$ no significant improvements in BMD were observed. ${ }^{105}$ In agreement with the findings of Gordon et al, ${ }^{105}$ administration of testosterone to young anorexic women for 12 months had no beneficial effect on BMD. ${ }^{125}$ To date, the efficacy of androgen therapy for improving low bone mass in female athletes as a result of the Triad has not been explored.

\section{Recombinant human insulin-like growth factor-I}

Research conducted prior to 2007 demonstrated that administration of recombinant human insulin-like growth 
factor-1 appeared to effectively increase lumbar spine areal BMD in anorexic women when used in combination with COC, ${ }^{106}$ most likely due to the synergistic effects of an anabolic therapy combined with an antiresorptive therapy. However, this combined therapy only increased BMD by $1.8 \%$ in 9 months. ${ }^{106}$ Such an approach weakly mimics the goals of a nonpharmacological approach to the Triad by improving circulating concentrations of insulin-like growth factor-1 and increasing bone formation via an improvement in energy status and by inhibiting bone resorption through restoration of adequate circulating concentrations of estrogen secondary to resumption of menses. Recent studies of recombinant human insulin-like growth factor-1 remain limited to the anorexic population, without a specific focus on athletes. ${ }^{131}$

\section{Recombinant human leptin}

Prior to 2007, investigators reported that administration of recombinant human leptin was associated with an increase in markers of bone formation among amenorrheic women; ${ }^{29}$ however, the effect of long-term recombinant human leptin treatment on BMD outcomes had not yet been explored. According to a recent study conducted in young women with functional hypothalamic amenorrhea due to strenuous exercise and/or low body weight, 36 weeks of treatment with recombinant human leptin resulted in a significant increase in levels of osteocalcin, a marker of bone formation. ${ }^{126}$ Subsequently, an open-label extension of this recombinant human leptin administration study for another 15 months (for a total study duration of 2 years) resulted in a significant increase in lumbar spine areal BMD (range 2.2\%-10.8\% increase from baseline) among completers $(n=4) .{ }^{37}$ According to these results, recombinant human leptin appears to be effective for improving BMD; however, it also resulted in weight loss due to the anorexigenic effects of leptin, ${ }^{37,126}$ an unfavorable and potentially dangerous outcome in a population of women who most likely need to gain rather than lose weight. As such, recombinant human leptin is not considered a therapeutic option for women with exercise-associated functional hypothalamic amenorrhea.

\section{Bisphosphonates}

Antiresorptive agents known as bisphosphonates are used clinically to treat osteoporosis and osteopenia in postmenopausal women and have been demonstrated to be efficacious in this population. ${ }^{132,133}$ However, bisphosphonates have teratogenic effects and stay in skeletal tissue for many years due to their long half-life; therefore, they are not recommended as a therapeutic option for women with reproductive potential. ${ }^{134}$ Furthermore, bisphosphonates may negatively impact skeletal growth during childhood, thereby providing an addition concern for use in adolescent athletes. ${ }^{134}$

Few investigators have explored the efficacy of bisphosphonates in improving bone health in premenopausal anorexic women or adolescents. ${ }^{125,127,128}$ Treatment with risedronate for 12 months in anorexic women resulted in a significant increase in posteroanterior lumbar spine areal $\mathrm{BMD}$, lateral spine areal BMD, and hip areal BMD by $3.2 \%, 3.8 \%$, and $1.9 \%$, respectively, compared with placebo. ${ }^{125}$ Anorexic adolescents who received alendronate for 12 months had an increase in areal BMD at the lumbar spine and femoral neck by $3.5 \%$ and $4.4 \%$, respectively. ${ }^{127}$ This change was significantly different from baseline, but not when compared with the change observed in the control group (2.2\% and $2.3 \%$, respectively). ${ }^{127}$ The weight gain experienced by both groups during the intervention was the strongest predictor of BMD change, thereby serving as a confounding factor in determining the ability of alendronate to improve bone mass in this population. ${ }^{127}$

To date, however, the impact of bisphosphonates on low bone mass in female athletes with the Triad has not been explored. Case studies of athletes with stress fractures demonstrate that intravenous treatment with bisphosphonates (pamidronate or ibandronate) for 4-8 weeks resulted in alleviation of pain within days ${ }^{135}$ to months ${ }^{136}$ after the commencement of therapy depending on injury site; in some cases, the athletes were able to resume their training regimen without pain 48-72 hours after the first treatment. ${ }^{135}$ However, it must be noted that bisphosphonates are not currently approved by the US Food and Drug Administration (FDA) for use in young, premenopausal athletes with low BMD or fractures; ${ }^{125,137}$ therefore, bisphosphonate therapy should only be implemented under the guidance of a specialist in endocrinology or metabolic bone diseases when athletes meet criteria for osteoporosis and are not responding to nonpharmacological treatment. ${ }^{94}$

\section{Other potential pharmacological agents}

In 2002 and 2010, the FDA approved teriparatide (parathyroid hormone [1-34]) and denosumab, respectively, as treatments for osteoporosis in postmenopausal women at high risk for fracture. ${ }^{138,139}$ Teriparatide, an anabolic agent unlike the other pharmacological agents currently approved for osteoporosis treatment, stimulates osteoblast action and consequent bone formation by inhibiting osteoblast apoptosis and enhancing 
osteoblast formation. ${ }^{140}$ Mechanistically, denosumab is an antiresorptive drug that decreases osteoclast action and consequent bone resorption by interfering with the binding of RANKL to its receptor RANK on osteoclasts. ${ }^{141}$ The binding of RANKL to RANK, which triggers bone resorption by allowing osteoclast formation and survival, ${ }^{141}$ is upregulated with estrogen deficiency due to the indirect relationship between circulating estrogen concentrations and RANKL expression. ${ }^{141,142}$ As such, denosumab counteracts the stimulatory effects of estrogen deficiency on bone resorption. ${ }^{141}$ Among postmenopausal women, these pharmaceutical agents effectively increase BMD and reduce fracture risk. ${ }^{143-146}$

Teriparatide and denosumab have not yet been studied in female athletes with low bone mass; however, two reports have been published describing the effects of teriparatide on bone mass in premenopausal women. ${ }^{147,148}$ Cohen et al ${ }^{147}$ observed a significant increase in areal BMD at the lumbar spine, total hip, and femoral neck, and in markers of bone formation during 24 months of teriparatide treatment in premenopausal women with idiopathic low bone mass. Further, transiliac bone biopsies revealed a significant increase in trabecular stiffness and trabecular number and a decrease in trabecular separation following 18 months of treatment with teriparatide. ${ }^{147}$ A case report of two women with metatarsal stress fractures demonstrated fracture healing as indicated by formation of a bony callus and radiographic evidence of new bone formation after 4 weeks of teriparatide treatment. ${ }^{148}$ Interestingly, in the case of one woman, prior treatment with an immobilizing boot for 6 weeks did not appear to promote much healing, suggesting that teriparatide aided fracture healing. ${ }^{148}$ However, these pharmacological therapies are not approved by the FDA for use in premenopausal women with low bone mass; therefore, their administration to young athletes is not recommended.

More research is necessary before a definitive decision can be made regarding optimal treatment for improvement of bone health in athletes suffering from one or more components of the Female Athlete Triad. The research to date suggests that nonpharmacological treatment should be the primary focus since it addresses the root of the problem, and pharmacological therapy should only be considered in special circumstances such as low BMD or a clinically significant fracture with a lack of favorable response to nonpharmacological therapy. ${ }^{94}$ Notably, there are currently no FDA-approved treatments for female athletes with low BMD. ${ }^{137}$ It is currently unknown how nonpharmacological and pharmacological treatments impact bone geometry and microarchitecture as well as the cortical and trabecular bone compartments, which are important areas of future research due to the synergistic influence of bone density, bone materials, and bone structure on bone strength, ${ }^{149-151}$ and the differing response of trabecular bone versus cortical bone to the energy-deficient and estrogen-deficient environment. ${ }^{3,49}$

\section{Conclusion}

Although often overlooked as a health consequence of low energy availability and menstrual dysfunction due to its silent manifestation, poor bone health in women with the Female Athlete Triad is characterized by detrimental changes in bone density and structure which, ultimately, may lead to clinical endpoints such as osteoporosis and fractures. These clinical consequences may be evident during adolescence or young adulthood when athletes may present with one or more of the Triad components, or may only be perceptible later in life, highlighting the most serious long-term ramification of the Triad. Effective prevention and treatment of the Triad are key factors for optimal health and well-being of female athletes. As such, there is a current need for prospective studies investigating the treatment of low bone mass and compromised bone microarchitecture in female athletes with low energy availability and functional hypothalamic amenorrhea to determine if bone health can be normalized to that of their eumenorrheic counterparts. Results from case studies and follow-up investigations of female athletes, as well as promising results from a nonpharmacological treatment approach focused on improving energy status and menstrual function among the anorexic population, are encouraging and provide the impetus for further exploration of such a strategy to address the low BMD and compromised bone structure found in female athletes with the Triad.

\section{Disclosure}

The authors report no conflicts of interest in this work.

\section{References}

1. De Souza MJ, Williams NI. Physiological aspects and clinical sequelae of energy deficiency and hypoestrogenism in exercising women. Hum Reprod Update. 2004;10(5):433-448.

2. Nattiv A, Loucks AB, Manore MM, Sanborn CF, Sundgot-Borgen J, Warren MP. American College of Sports Medicine position stand. The female athlete Triad. Med Sci Sports Exerc. 2007;39(10):1867-1882.

3. Ackerman KE, Nazem T, Chapko D, et al. Bone microarchitecture is impaired in adolescent amenorrheic athletes compared with eumenorrheic athletes and nonathletic controls. J Clin Endocrinol Metab. 2011;96(10): 3123-3133.

4. Barrack MT, Gibbs JC, De Souza MJ, et al. Higher incidence of bone stress injury with increasing Female Athlete Triad-related risk factors: a prospective multisite study of exercising girls and women. Am J Sports Med. 2014 Feb 24. [Epub ahead of print]. 
5. Hosmer WD, Genant HK, Browner WS. Fractures before menopause: a red flag for physicians. Osteoporos Int. 2002;13(4):337-341.

6. Wu F, Mason B, Horne A, et al. Fractures between the ages of 20 and 50 years increase women's risk of subsequent fractures. Arch Intern Med. 2002;162(1):33-36.

7. Rickenlund A, Eriksson MJ, Schenck-Gustafsson K, Hirschberg AL. Amenorrhea in female athletes is associated with endothelial dysfunction and unfavorable lipid profile. J Clin Endocrinol Metab. 2005;90(3): 1354-1359.

8. Zeni Hoch A, Dempsey RL, Carrera GF, et al. Is there an association between athletic amenorrhea and endothelial cell dysfunction? Med Sci Sports Exerc. 2003;35(3):377-383.

9. Torstveit MK, Sundgot-Borgen J. The female athlete Triad exists in both elite athletes and controls. Med Sci Sports Exerc. 2005;37(9): 1449-1459.

10. Gibbs JC, Williams NI, De Souza MJ. Prevalence of individual and combined components of the female athlete Triad. Med Sci Sports Exerc. 2013;45(5):985-996.

11. Loucks AB. Low energy availability in the marathon and other endurance sports. Sports Med. 2007;37(4-5):348-352.

12. Loucks AB, Verdun M, Heath EM. Low energy availability, not stress of exercise, alters LH pulsatility in exercising women. J Appl Physiol. 1998;84(1):37-46.

13. Loucks AB, Thuma JR. Luteinizing hormone pulsatility is disrupted at a threshold of energy availability in regularly menstruating women. J Clin Endocrinol Metab. 2003;88(1):297-2311.

14. De Souza MJ, Lee DK, VanHeest JL, Scheid JL, West SL, Williams NI. Severity of energy-related menstrual disturbances increases in proportion to indices of energy conservation in exercising women. Fertil Steril. 2007;88(4):971-975.

15. Ihle R, Loucks AB. Dose-response relationships between energy availability and bone turnover in young exercising women. $J$ Bone Miner Res. 2004;19(8):1231-1240.

16. De Souza MJ, West SL, Jamal SA, Hawker GA, Gundberg CM, Williams NI. The presence of both an energy deficiency and estrogen deficiency exacerbate alterations of bone metabolism in exercising women. Bone. 2008;43(1):140-148.

17. Scheid JL, Toombs RJ, Ducher G, Gibbs JC, Williams NI, De Souza MJ. Estrogen and peptide YY are associated with bone mineral density in premenopausal exercising women. Bone. 2011;49(2):194-201.

18. Hotta M, Fukuda I, Sato K, Hizuka N, Shibasaki T, Takano K. The relationship between bone turnover and body weight, serum insulinlike growth factor (IGF) I, and serum IGF-binding protein levels in patients with anorexia nervosa. J Clin Endocrinol Metab. 2000;85(1): 200-206.

19. Christo K, Cord J, Mendes N, et al. Acylated ghrelin and leptin in adolescent athletes with amenorrhea, eumenorrheic athletes and controls: a cross-sectional study. Clin Endocrinol (Oxf). 2008;69(4):628-633.

20. De Souza MJ, Leidy HJ, O’Donnell E, Lasley B, Williams NI. Fasting ghrelin levels in physically active women: relationship with menstrual disturbances and metabolic hormones. J Clin Endocrinol Metab. 2004;89(7):3536-3542.

21. Scheid JL, Williams NI, West SL, VanHeest JL, De Souza MJ. Elevated PYY is associated with energy deficiency and indices of subclinical disordered eating in exercising women with hypothalamic amenorrhea. Appetite. 2009;52(1):184-192.

22. Chan JL, Mantzoros CS. Role of leptin in energy-deprivation states: normal human physiology and clinical implications for hypothalamic amenorrhoea and anorexia nervosa. Lancet. 2005;366(9479):74-85.

23. Russell M, Misra M. Influence of ghrelin and adipocytokines on bone mineral density in adolescent female athletes with amenorrhea and eumenorrheic athletes. Med Sport Sci. 2010;55:103-113.

24. Wade GN, Schneider JE, Li HY. Control of fertility by metabolic cues. Am J Physiol. 1996;270(1 Pt 1):E1-E19.

25. Mantzoros CS, Magkos F, Brinkoetter M, et al. Leptin in human physiology and pathophysiology. Am J Physiol Endocrinol Metab. 2011;301(4):E567-E584.
26. De Souza MJ, Toombs RJ, Scheid JL, O’Donnell E, West SL, Williams NI. High prevalence of subtle and severe menstrual disturbances in exercising women: confirmation using daily hormone measures. Hum Reprod. 2010;25(2):491-503.

27. The Practice Committee of the American Society for Reproductive Medicine. Current evaluation of amenorrhea. Fertil Steril. 2008;90(5): S219-S225.

28. Ackerman KE, Slusarz K, Guereca G, et al. Higher ghrelin and lower leptin secretion are associated with lower LH secretion in young amenorrheic athletes compared with eumenorrheic athletes and controls. $\mathrm{Am}$ J Physiol Endocrinol Metab. 2012;302(7):E800-E806.

29. Welt CK, Chan JL, Bullen J, et al. Recombinant human leptin in women with hypothalamic amenorrhea. $N$ Engl J Med. 2004;351(10): 987-997.

30. Loucks AB, Mortola JF, Girton L, Yen SS. Alterations in the hypothalamic-pituitary-ovarian and the hypothalamic-pituitary-adrenal axes in athletic women. J Clin Endocrinol Metab. 1989;68(2): 402-411.

31. Williams NI, Young JC, McArthur JW, Bullen B, Skrinar GS, Turnbull B. Strenuous exercise with caloric restriction: effect on luteinizing hormone secretion. Med Sci Sports Exerc. 1995;27(10):1390-1398.

32. Scheid JL, De Souza MJ, Hill BR, Leidy HJ, Williams NI. Decreased luteinizing hormone pulse frequency is associated with elevated 24-hour ghrelin after calorie restriction and exercise in premenopausal women. Am J Physiol Endocrinol Metab. 2013;304(1):E109-E116.

33. Veldhuis JD, Evans WS, Demers LM, Thorner MO, Wakat D, Rogol AD. Altered neuroendocrine regulation of gonadotropin secretion in women distance runners. J Clin Endocrinol Metab. 1985;61(3):557-563.

34. De Souza MJ, Miller BE, Loucks AB, et al. High frequency of luteal phase deficiency and anovulation in recreational women runners: blunted elevation in follicle-stimulating hormone observed during luteal-follicular transition. J Clin Endocrinol Metab. 1998;83(12): 4220-4232.

35. Williams NI, Reed JL, Leidy HJ, Legro RS, De Souza MJ. Estrogen and progesterone exposure is reduced in response to energy deficiency in women aged 25-40 years. Hum Reprod. 2010;25(9):2328-2339.

36. Berga S, Naftolin F. Neuroendocrine control of ovulation. Gynecol Endocrinol. 2012;28 Suppl 1:9-13.

37. Sienkiewicz E, Magkos F, Aronis KN, et al. Long-term metreleptin treatment increases bone mineral density and content at the lumbar spine of lean hypoleptinemic women. Metabolism. 2011;60(9):1211-1221.

38. Compston JE. Sex steroids and bone. Physiol Rev. 2001;81(1): 419-447.

39. Nelson ME, Fisher EC, Catsos PD, Meredith CN, Turksoy RN, Evans WJ. Diet and bone status in amenorrheic runners. Am J Clin Nutr. 1986;43(6):910-916.

40. Drinkwater BL, Bruemner B, Chesnut CH 3rd. Menstrual history as a determinant of current bone density in young athletes. JAMA. 1990;263(4):545-548.

41. Drinkwater BL, Nilson K, Chesnut CH 3rd, Bremner WJ, Shainholtz S, Southworth MB. Bone mineral content of amenorrheic and eumenorrheic athletes. $N$ Engl J Med. 1984;311(5):277-281.

42. Rencken ML, Chesnut $\mathrm{CH}$ 3rd, Drinkwater BL. Bone density at multiple skeletal sites in amenorrheic athletes. JAMA. 1996;276(3):238-240.

43. Christo K, Prabhakaran R, Lamparello B, et al. Bone metabolism in adolescent athletes with amenorrhea, athletes with eumenorrhea, and control subjects. Pediatrics. 2008;121(6):1127-1136.

44. West SL, Scheid JL, De Souza MJ. The effect of exercise and estrogen on osteoprotegerin in premenopausal women. Bone. 2009;44(1): 137-144.

45. Mallinson RJ, Williams NI, Hill BR, De Souza MJ. Body composition and reproductive function exert unique influences on indices of bone health in exercising women. Bone. 2013;56(1):91-100.

46. Temme KE, Hoch AZ. Recognition and rehabilitation of the female athlete Triad/tetrad: a multidisciplinary approach. Curr Sports Med Rep. 2013;12(3):190-199.

47. Barrack MT, Ackerman KE, Gibbs JC. Update on the female athlete Triad. Curr Rev Musculoskelet Med. 2013;6(2):195-204. 
48. Carter DR, Bouxsein ML, Marcus R. New approaches for interpreting projected bone densitometry data. J Bone Miner Res. 1992;7(2): 137-145.

49. Ackerman KE, Putman M, Guereca G, et al. Cortical microstructure and estimated bone strength in young amenorrheic athletes, eumenorrheic athletes and non-athletes. Bone. 2012;51(4):680-687.

50. Ducher G, Eser P, Hill B, Bass S. History of amenorrhoea compromises some of the exercise-induced benefits in cortical and trabecular bone in the peripheral and axial skeleton: a study in retired elite gymnasts. Bone. 2009;45(4):760-767.

51. To WW, Wong MW, Lam IY. Bone mineral density differences between adolescent dancers and non-exercising adolescent females. J Pediatr Adolesc Gynecol. 2005;18(5):337-342.

52. Seeman E. Periosteal bone formation - a neglected determinant of bone strength. N Engl J Med. 2003;349(4):320-323.

53. Ducher G, Turner AI, Kukuljan S, et al. Obstacles in the optimization of bone health outcomes in the female athlete Triad. Sports Med. 2011;41(7):587-607.

54. Stratec Medizintechnik GmbH. XCT 3000 Manual: software version 6.00. Pforzheim, Germany; 2007.

55. Schiessl H, Ferretti JL, Tysarczyk-Niemeyer G, Willnecker J. Noninvasive bone strength index as analyzed by peripheral quantitative computed tomography (pQCT). In: Schonau E, editor. Paediatric Osteology: New Developments in Diagnostics and Therapy. Amsterdam, The Netherlands: Elsevier; 1996.

56. Schoenau E, Neu CM, Rauch F, Manz F. The development of bone strength at the proximal radius during childhood and adolescence. J Clin Endocrinol Metab. 2001;86(2):613-618.

57. Yoshikawa T, Turner CH, Peacock M, et al. Geometric structure of the femoral neck measured using dual-energy x-ray absorptiometry. J Bone Miner Res. 1994;9(7):1053-1064.

58. Beck TJ, Ruff CB, Warden KE, Scott WW Jr, Rao GU. Predicting femoral neck strength from bone mineral data. A structural approach. Invest Radiol. 1990;25(1):6-18.

59. Beck T. Measuring the structural strength of bones with dual-energy X-ray absorptiometry: principles, technical limitations, and future possibilities. Osteoporos Int. 2003;14 Suppl 5:S81-S88.

60. Ackerman KE, Pierce L, Guereca G, et al. Hip structural analysis in adolescent and young adult oligoamenorrheic and eumenorrheic athletes and nonathletes. J Clin Endocrinol Metab. 2013;98(4): 1742-1749.

61. Duckham RL, Peirce N, Bailey CA, Summers G, Cameron N, Brooke-Wavell K. Bone geometry according to menstrual function in female endurance athletes. Calcif Tissue Int. 2013;92(5): 444-450.

62. Looker AC. Femur neck bone mineral density and fracture risk by age, sex, and race or Hispanic origin in older US adults from NHANES III. Arch Osteoporos. 2013;8(1-2):141.

63. Goolsby MA, Barrack MT, Nattiv A. A displaced femoral neck stress fracture in an amenorrheic adolescent female runner. Sports Health. 2012;4(4):352-356.

64. Nikander R, Sievanen H, Heinonen A, Kannus P. Femoral neck structure in adult female athletes subjected to different loading modalities. $J$ Bone Miner Res. 2005;20(3):520-528.

65. Nikander R, Sievanen H, Uusi-Rasi K, Heinonen A, Kannus P. Loading modalities and bone structures at nonweight-bearing upper extremity and weight-bearing lower extremity: a pQCT study of adult female athletes. Bone. 2006;39(4):886-894.

66. Nikander R, Kannus P, Dastidar P, et al. Targeted exercises against hip fragility. Osteoporos Int. 2009;20(8):1321-1328.

67. Nikander R, Kannus P, Rantalainen T, Uusi-Rasi K, Heinonen A, Sievanen H. Cross-sectional geometry of weight-bearing tibia in female athletes subjected to different exercise loadings. Osteoporos Int. 2010;21(10):1687-1694.

68. Nichols JF, Rauh MJ, Barrack MT, Barkai HS. Bone mineral density in female high school athletes: interactions of menstrual function and type of mechanical loading. Bone. 2007;41(3):371-377.
69. Theintz G, Buchs B, Rizzoli R, et al. Longitudinal monitoring of bone mass accumulation in healthy adolescents: evidence for a marked reduction after 16 years of age at the levels of lumbar spine and femoral neck in female subjects. J Clin Endocrinol Metab. 1992;75(4):1060-1065.

70. Bailey DA, McKay HA, Mirwald RL, Crocker PR, Faulkner RA. A six-year longitudinal study of the relationship of physical activity to bone mineral accrual in growing children: the University of Saskatchewan Bone Mineral Accrual Study. J Bone Miner Res. 1999; 14(10):1672-1679.

71. Bonjour JP, Theintz G, Buchs B, Slosman D, Rizzoli R. Critical years and stages of puberty for spinal and femoral bone mass accumulation during adolescence. J Clin Endocrinol Metab. 1991;73(3):555-563.

72. Bachrach LK. Acquisition of optimal bone mass in childhood and adolescence. Trends Endocrinol Metab. 2001;12(1):22-28.

73. Gibbs JC, Nattiv A, Barrack MT, et al. Low bone density risk is higher in exercising women with multiple Triad risk factors. Med Sci Sports Exerc. 2014;46(1):167-176.

74. Warden SJ, Burr DB, Brukner PD. Stress fractures: pathophysiology, epidemiology, and risk factors. Curr Osteoporos Rep. 2006;4(3): 103-109.

75. Schnackenburg KE, Macdonald HM, Ferber R, Wiley JP, Boyd SK. Bone quality and muscle strength in female athletes with lower limb stress fractures. Med Sci Sports Exerc. 2011;43(11):2110-2119.

76. Chen YT, Tenforde AS, Fredericson M. Update on stress fractures in female athletes: epidemiology, treatment, and prevention. Curr Rev Musculoskelet Med. 2013;6(2):173-181.

77. Nattiv A, Kennedy G, Barrack MT, et al. Correlation of MRI grading of bone stress injuries with clinical risk factors and return to play: a 5-year prospective study in collegiate track and field athletes. $A m ~ J$ Sports Med. 2013;41(8):1930-1941.

78. Arendt E, Agel J, Heikes C, Griffiths H. Stress injuries to bone in college athletes: a retrospective review of experience at a single institution. $\mathrm{Am}$ J Sports Med. 2003;31(6):959-968.

79. Brunet ME, Cook SD, Brinker MR, Dickinson JA. A survey of running injuries in 1505 competitive and recreational runners. J Sports Med Phys Fitness. 1990;30(3):307-315.

80. Johnson AW, Weiss CB Jr, Wheeler DL. Stress fractures of the femoral shaft in athletes - more common than expected. A new clinical test. Am J Sports Med. 1994;22(2):248-256.

81. Duckham RL, Peirce N, Meyer C, Summers GD, Cameron N, Brooke-Wavell K. Risk factors for stress fracture in female endurance athletes: a cross-sectional study. BMJ Open. 2012;2(6).

82. Fredericson M, Kent K. Normalization of bone density in a previously amenorrheic runner with osteoporosis. Med Sci Sports Exerc. 2005;37(9):1481-1486.

83. Zanker CL, Cooke CB, Truscott JG, Oldroyd B, Jacobs HS. Annual changes of bone density over 12 years in an amenorrheic athlete. Med Sci Sports Exerc. 2004;36(1):137-142.

84. Mallinson RJ, Williams NI, Olmsted MP, Scheid JL, Riddle ES, De Souza MJ. A case report of recovery of menstrual function following a nutritional intervention in two exercising women with amenorrhea of varying duration. J Int Soc Sports Nutr. 2013;10(1):34.

85. Keen AD, Drinkwater BL. Irreversible bone loss in former amenorrheic athletes. Osteoporos Int. 1997;7(4):311-315.

86. Drinkwater BL, Nilson K, Ott S, Chesnut $\mathrm{CH}$ 3rd. Bone mineral density after resumption of menses in amenorrheic athletes. JAMA. 1986;256(3):380-382.

87. Jonnavithula S, Warren MP, Fox RP, Lazaro MI. Bone density is compromised in amenorrheic women despite return of menses: a 2-year study. Obstet Gynecol. 1993;81(5 Pt 1):669-674.

88. Warren MP, Brooks-Gunn J, Fox RP, Holderness CC, Hyle EP, Hamilton WG. Osteopenia in exercise-associated amenorrhea using ballet dancers as a model: a longitudinal study. J Clin Endocrinol Metab. 2002;87(7):3162-3168.

89. Hind K, Zanker C, Truscott J. Five-year follow-up investigation of bone mineral density by age in premenopausal elite-level long-distance runners. Clin J Sport Med. 2011;21(6):521-529. 
90. Miller KK, Lee EE, Lawson EA, et al. Determinants of skeletal loss and recovery in anorexia nervosa. J Clin Endocrinol Metab. 2006;91(8): 2931-2937.

91. Misra M, Prabhakaran R, Miller KK, et al. Weight gain and restoration of menses as predictors of bone mineral density change in adolescent girls with anorexia nervosa-1. J Clin Endocrinol Metab. 2008;93(4): 1231-1237.

92. Bolton JG, Patel S, Lacey JH, White S. A prospective study of changes in bone turnover and bone density associated with regaining weight in women with anorexia nervosa. Osteoporos Int. 2005;16(12): 1955-1962.

93. Dominguez J, Goodman L, Sen Gupta S, et al. Treatment of anorexia nervosa is associated with increases in bone mineral density, and recovery is a biphasic process involving both nutrition and return of menses. Am J Clin Nutr. 2007;86(1):92-99.

94. De Souza MJ, Nattiv A, Joy E, et al. 2014 Female Athlete Triad Coalition Consensus Statement on Treatment and Return to Play of the Female Athlete Triad: 1st International Conference held in San Francisco, California, May 2012 and 2nd International Conference held in Indianapolis, Indiana, May 2013. Br J Sports Med. 2014; 48(4):289.

95. Institute of Medicine. Dietary Reference Intakes for Calcium and Vitamin D. November 2010 Report Brief. National Academy of Sciences. Available from: http://www.iom.edu/ /media/Files/ Report\%20Files/2010/Dietary-Reference-Intakes-for-Calciumand-Vitamin-D/Vitamin\%20D\%20and\%20Calcium\%202010\%20 Report\%20Brief.pdf. Accessed January 26, 2014.

96. Rosen CJ, Gallagher JC. The 2011 IOM report on vitamin D and calcium requirements for North America: clinical implications for providers treating patients with low bone mineral density. $J$ Clin Densitom. 2011;14(2):79-84.

97. Holick MF, Binkley NC, Bischoff-Ferrari HA, et al. Evaluation, treatment, and prevention of vitamin D deficiency: an Endocrine Society clinical practice guideline. J Clin Endocrinol Metab. 2011;96(7): 1911-1930.

98. Winett RA, Carpinelli RN. Potential health-related benefits of resistance training. Prev Med. 2001;33(5):503-513.

99. Loud KJ, Gordon CM, Micheli LJ, Field AE. Correlates of stress fractures among preadolescent and adolescent girls. Pediatrics. 2005;115(4):e399-e406.

100. Petit MA, Beck TJ, Lin HM, Bentley C, Legro RS, Lloyd T. Femoral bone structural geometry adapts to mechanical loading and is influenced by sex steroids: the Penn State Young Women's Health Study. Bone. 2004;35(3):750-759.

101. Cobb KL, Bachrach LK, Sowers M, et al. The effect of oral contraceptives on bone mass and stress fractures in female runners. Med Sci Sports Exerc. 2007;39(9):1464-1473.

102. Hergenroeder AC, Smith EO, Shypailo R, Jones LA, Klish WJ, Ellis $\mathrm{K}$. Bone mineral changes in young women with hypothalamic amenorrhea treated with oral contraceptives, medroxyprogesterone, or placebo over 12 months. Am J Obstet Gynecol. 1997;176(5): 1017-1025.

103. Castelo-Branco C, Vicente JJ, Pons F, Martinez de Osaba MJ, Casals E, Vanrell JA. Bone mineral density in young, hypothalamic oligoamenorrheic women treated with oral contraceptives. J Reprod Med. 2001;46(10):875-879.

104. Rickenlund A, Carlstrom K, Ekblom B, Brismar TB, Von Schoultz B, Hirschberg AL. Effects of oral contraceptives on body composition and physical performance in female athletes. J Clin Endocrinol Metab. 2004;89(9):4364-4370.

105. Gordon CM, Grace E, Emans SJ, et al. Effects of oral dehydroepiandrosterone on bone density in young women with anorexia nervosa: a randomized trial. J Clin Endocrinol Metab. 2002;87(11):4935-4941.

106. Grinspoon S, Thomas L, Miller K, Herzog D, Klibanski A. Effects of recombinant human IGF-I and oral contraceptive administration on bone density in anorexia nervosa. J Clin Endocrinol Metab. 2002;87(6):2883-2891.
107. Strokosch GR, Friedman AJ, Wu SC, Kamin M. Effects of an oral contraceptive (norgestimate/ethinyl estradiol) on bone mineral density in adolescent females with anorexia nervosa: a double-blind, placebocontrolled study. J Adolesc Health. 2006;39(6):819-827.

108. De Cree C, Lewin R, Ostyn M. Suitability of cyproterone acetate in the treatment of osteoporosis associated with athletic amenorrhea. Int J Sports Med. 1988;9(3):187-192.

109. Gremion G, Rizzoli R, Slosman D, Theintz G, Bonjour JP. Oligo-amenorrheic long-distance runners may lose more bone in spine than in femur. Med Sci Sports Exerc. 2001;33(1):15-21.

110. Golden NH, Lanzkowsky L, Schebendach J, Palestro CJ, Jacobson MS, Shenker IR. The effect of estrogen-progestin treatment on bone mineral density in anorexia nervosa. J Pediatr Adolesc Gynecol. 2002;15(3):135-143.

111. Munoz MT, Morande G, Garcia-Centenera JA, Hervas F, Pozo J, Argente J. The effects of estrogen administration on bone mineral density in adolescents with anorexia nervosa. Eur $J$ Endocrinol. 2002;146(1):45-50.

112. Klibanski A, Biller BM, Schoenfeld DA, Herzog DB, Saxe VC. The effects of estrogen administration on trabecular bone loss in young women with anorexia nervosa. J Clin Endocrinol Metab. 1995;80(3):898-904.

113. Warren MP, Miller KK, Olson WH, Grinspoon SK, Friedman AJ. Effects of an oral contraceptive (norgestimate/ethinyl estradiol) on bone mineral density in women with hypothalamic amenorrhea and osteopenia: an open-label extension of a doubleblind, placebo-controlled study. Contraception. 2005;72(3): 206-211.

114. Seeman E, Szmukler GI, Formica C, Tsalamandris C, Mestrovic R. Osteoporosis in anorexia nervosa: the influence of peak bone density, bone loss, oral contraceptive use, and exercise. J Bone Miner Res. 1992;7(12):1467-1474.

115. Divasta AD, Feldman HA, Giancaterino C, Rosen CJ, Leboff MS, Gordon CM. The effect of gonadal and adrenal steroid therapy on skeletal health in adolescents and young women with anorexia nervosa. Metabolism. 2012;61(7):1010-1020.

116. Gibson JH, Mitchell A, Reeve J, Harries MG. Treatment of reduced bone mineral density in athletic amenorrhea: a pilot study. Osteoporos Int. 1999;10(4):284-289.

117. Warren MP, Brooks-Gunn J, Fox RP, et al. Persistent osteopenia in ballet dancers with amenorrhea and delayed menarche despite hormone therapy: a longitudinal study. Fertil Steril. 2003;80(2): 398-404.

118. Cumming DC. Exercise-associated amenorrhea, low bone density, and estrogen replacement therapy. Arch Intern Med. 1996;156(19): 2193-2195.

119. Karlsson MK, Weigall SJ, Duan Y, Seeman E. Bone size and volumetric density in women with anorexia nervosa receiving estrogen replacement therapy and in women recovered from anorexia nervosa. J Clin Endocrinol Metab. 2000;85(9):3177-3182.

120. Patel S. Effect of hormone replacement therapy on bone density in a patient with severe osteoporosis caused by anorexia nervosa. Ann Rheum Dis. 1999;58(1):66.

121. Misra M, Katzman D, Miller KK, et al. Physiologic estrogen replacement increases bone density in adolescent girls with anorexia nervosa. J Bone Miner Res. 2011;26(10):2430-2438.

122. Legroux-Gerot I, Vignau J, Collier F, Cortet B. Factors influencing changes in bone mineral density in patients with anorexia nervosarelated osteoporosis: the effect of hormone replacement therapy. Calcif Tissue Int. 2008;83(5):315-323.

123. Gordon CM, Grace E, Emans SJ, Goodman E, Crawford MH, Leboff MS. Changes in bone turnover markers and menstrual function after short-term oral DHEA in young women with anorexia nervosa. J Bone Miner Res. 1999;14(1):136-145.

124. Miller KK, Grieco KA, Klibanski A. Testosterone administration in women with anorexia nervosa. J Clin Endocrinol Metab. 2005;90(3): $1428-1433$. 
125. Miller KK, Meenaghan E, Lawson EA, et al. Effects of risedronate and low-dose transdermal testosterone on bone mineral density in women with anorexia nervosa: a randomized, placebo-controlled study. J Clin Endocrinol Metab. 2011;96(7):2081-2088.

126. Chou SH, Chamberland JP, Liu X, et al. Leptin is an effective treatment for hypothalamic amenorrhea. Proc Natl Acad Sci USA. 2011;108(16):6585-6590.

127. Golden NH, Iglesias EA, Jacobson MS, et al. Alendronate for the treatment of osteopenia in anorexia nervosa: a randomized, double-blind, placebocontrolled trial. J Clin Endocrinol Metab. 2005;90(6):3179-3185.

128. Miller KK, Grieco KA, Mulder J, et al. Effects of risedronate on bone density in anorexia nervosa. J Clin Endocrinol Metab. 2004;89(8): 3903-3906.

129. Vescovi JD, Jamal SA, De Souza MJ. Strategies to reverse bone loss in women with functional hypothalamic amenorrhea: a systematic review of the literature. Osteoporos Int. 2008;19(4):465-478.

130. Sim LA, McGovern L, Elamin MB, Swiglo BA, Erwin PJ, Montori VM. Effect on bone health of estrogen preparations in premenopausal women with anorexia nervosa: a systematic review and meta-analyses. Int $J$ Eat Disord. 2010;43(3):218-225.

131. Misra M, McGrane J, Miller KK, et al. Effects of rhIGF-1 administration on surrogate markers of bone turnover in adolescents with anorexia nervosa. Bone. 2009;45(3):493-498.

132. Khosla S, Bilezikian JP, Dempster DW, et al. Benefits and risks of bisphosphonate therapy for osteoporosis. J Clin Endocrinol Metab. 2012;97(7):2272-2282.

133. Yates J. A meta-analysis characterizing the dose-response relationships for three oral nitrogen-containing bisphosphonates in postmenopausal women. Osteoporos Int. 2013;24(1):253-262.

134. Shima Y, Engebretsen L, Iwasa J, Kitaoka K, Tomita K. Use of bisphosphonates for the treatment of stress fractures in athletes. Knee Surg Sports Traumatol Arthrosc. 2009;17(5):542-550.

135. Stewart GW, Brunet ME, Manning MR, Davis FA. Treatment of stress fractures in athletes with intravenous pamidronate. Clin J Sport Med. 2005;15(2):92-94.

136. Chambers SA, Clarke A, Wolman R. Treatment of lumbar pars interarticularis stress injuries in athletes with intravenous bisphosphonates: five case studies. Clin J Sport Med. 2011;21(2):141-143.

137. Bachrach LK, Sills IN. Clinical report-bone densitometry in children and adolescents. Pediatrics. 2011;127(1):189-194.

138. Food and Drug Administration. Drugs@FDA: FDA Approved Drug Products. FORTEO. Available from: http://www.accessdata.fda.gov/ scripts/cder/drugsatfda/index.cfm?fuseaction=Search.DrugDetails. Accessed January 26, 2014.
139. Food and Drug Administration. Drugs@FDA: FDA Approved Drug Products. PROLIA. Available from: http://www.accessdata.fda.gov/ scripts/cder/drugsatfda/index.cfm?fuseaction=Search.SearchActio n\&searchTerm=denosumab\&SearchType=BasicSearch. Accessed January 26, 2014.

140. Cosman F, Lindsay R. Therapeutic potential of parathyroid hormone. Curr Osteoporos Rep. 2004;2(1):5-11.

141. Josse R, Khan A, Ngui D, Shapiro M. Denosumab, a new pharmacotherapy option for postmenopausal osteoporosis. Curr Med Res Opin. 2013;29(3):205-216.

142. Baron R, Ferrari S, Russell RG. Denosumab and bisphosphonates: different mechanisms of action and effects. Bone. 2011;48(4): 677-692.

143. Neer RM, Arnaud CD, Zanchetta JR, et al. Effect of parathyroid hormone (1-34) on fractures and bone mineral density in postmenopausal women with osteoporosis. $N$ Engl J Med. 2001;344(19): 1434-1441.

144. Genant HK, Libanati C, Engelke K, et al. Improvements in hip trabecular, subcortical, and cortical density and mass in postmenopausal women with osteoporosis treated with denosumab. Bone. 2013;56(2): 482-488.

145. Recknor C, Czerwinski E, Bone HG, et al. Denosumab compared with ibandronate in postmenopausal women previously treated with bisphosphonate therapy: a randomized open-label trial. Obstet Gynecol. 2013;121(6):1291-1299.

146. Tsai JN, Uihlein AV, Lee H, et al. Teriparatide and denosumab, alone or combined, in women with postmenopausal osteoporosis: the DATA study randomised trial. Lancet. 2013;382(9886):50-56.

147. Cohen A, Stein EM, Recker RR, et al. Teriparatide for idiopathic osteoporosis in premenopausal women: a pilot study. J Clin Endocrinol Metab. 2013;98(5):1971-1981.

148. Raghavan P, Christofides E. Role of teriparatide in accelerating metatarsal stress fracture healing: a case series and review of literature. Clin Med Insights Endocrinol Diabetes. 2012;5:39-45.

149. Adams JE. Advances in bone imaging for osteoporosis. Nat Rev Endocrinol. 2013;9(1):28-42.

150. Davison KS, Siminoski K, Adachi JD, et al. Bone strength: the whole is greater than the sum of its parts. Semin Arthritis Rheum. 2006;36(1):22-31.

151. Bouxsein ML. Bone quality: where do we go from here? Osteoporos Int. 2003;14 Suppl 5:S118-S127.
International Journal of Women's Health

\section{Publish your work in this journal}

The International Journal of Women's Health is an international, peerreviewed open-access journal publishing original research, reports, editorials, reviews and commentaries on all aspects of women's healthcare including gynecology, obstetrics, and breast cancer. The manuscript management system is completely online and includes

\section{Dovepress}

a very quick and fair peer-review system, which is all easy to use. Visit http://www.dovepress.com/testimonials.php to read real quotes from published authors. 